\title{
DISCUTINDO A QUESTÃO DA ALTERIDADE EM HUSSERL E RICOEUR
}

\author{
Elton Moreira Quadros ${ }^{1}$ \\ Universidade do Estado da Bahia (UNEB) \\ (D) https://orcid.org/0000-0003-2802-5990
}

\section{RESUMO:}

Discutimos a concepção de alteridade presente na $\mathrm{V}$ meditação cartesiana de Husserl através da perspectiva ricoeuriana, bem como, a proposta de Ricoeur que coloca a alteridade no centro da ipseidade. Ricoeur, ao pensar sobre a alteridade, acompanha com atenção o desenvolver do pensamento de Husserl e pretende compreender os caminhos que levam do eu (ego) ao outro (alter) através do mundo em que estamos inseridos enquanto comunidade. A afirmação ricoeuriana da subjetividade (Ipseidade) pressupõe permanentemente a relação eu-outro-mundo. Portanto, para o filósofo francês, perseguir a compreensão husserliana de alteridade contribui, não somente para confrontar o seu próprio pensamento, como para aprofundar a sua concepção relacional da condição humana.

PALAVRAS-CHAVE: Ipseidade; Memória; Subjetividade

\section{DISCUSSING RICOEUR'S AND HUSSERL'S NOTION OF ALTERITY}

\begin{abstract}
:
We discuss Husserl's conception of alterity approached in the Fifth Cartesian Medidation from a ricoeurian perspective. We also discuss Ricoeur's proposition which puts alterity at the core of ipseity. When Ricouer thinks about alterity, he follows the evolution of Husserl's thought and intends to understand the ways that conducts from me (ego) to theother (alter) through the world in which we are inserted as a community. The ricouerian statement on subjectivity (ipseity) constantly presupposes the relation self-other-world. Therefore according to the French philosopher, to seek husserlian understanding of alterity contributes not only to face his own thought, but also to deepen his relational conception on human condition.
\end{abstract}

\footnotetext{
${ }^{1}$ Doutor e professor da Universidade do Estado da Bahia (UNEB), Bahia - Brasil. E-mail: emquadros@uneb.br
} 
KEYWORDS: Ipseity; Memory; Subjectivity.

\section{Considerações iniciais}

Neste artigo intentamos realizar uma análise da questão da alteridade, relacionando à ao processo interno de desenvolvimento dessa questão no pensamento de Ricoeur. Se o si-mesmo constitui um ponto efetivo do reconhecimento de si, essa "identidade própria", só pode ser pensada, para Ricoeur, em relação com a alteridade, mais que isso, como alteridade. Ipseidade e alteridade constituem um par indissociado e indissociável para o autor.

Para tanto, trazemos a discussão crítica realizada pelo filósofo francês com o pensamento de Husserl, principalmente, a partir da obra Meditações cartesianas com o foco quase que específico na "V Meditação", quando o filósofo alemão coloca a alteridade como uma questão que parte da egologia e alcança a compreensão do outro como alter ego. A análise aqui desenvolvida está relacionada, especialmente, com dois livros de Ricoeur: Na escola da fenomenologia e $O$ si-mesmo como um outro (2014) e pretende realizar uma compreensão da alteridade em sua dinamicidade, tanto no pensamento de Husserl, origem da discussão segundo Ricoeur, como no próprio pensamento de Ricoeur, quando consegue a partir da reflexão husserliana, evidar seu próprio caminho, consideramos importante o caminho que apresenta um percurso que parte do ego e alcance o outro, os outros.

\section{Do ego à comunidade: considerações a partir do pensamento de Husserl}

\section{Solipsismo e alteridade}

A primeira questão posta por Ricoeur, ao refletir sobre o tema da alteridade, parte da discussão do pensamento de Husserl, e do aparecimento do problema do outro dentro da fenomenologia transcendental ${ }^{2}$. Esse problema consiste na indicação de uma objeção ao solipsismo no início da "V Meditação Cartesiana", essa é a "objeção no curso de uma meditação realizada pelo eu sobre o si mesmo" (RICOEUR, 2009, p. 216). Assim, Husserl precisa responder essa crítica e explicar que os outros egos "não são por certo simples representações e objetos representados em mim em unidades sintáticas de um processo de verificação que se desenvolve 'em mim', mas justamente nos 'outros"” (HUSSERL, 2001, p. 105).

\footnotetext{
${ }^{2}$ A utilização do termo transcendental está associado, no pensamento de Husserl, numa busca pela fonte originária do conhecimento e do saber, na medida em que procura compreender a vida em sua plenitude de sentido. Com base nisso, a consciência ou subjetividade sempre são compreendidas como transcendental e como fundamento.
} 
Segundo Ricoeur toda vez que houve uma objeção ao solipsismo, isso sempre partiu do senso comum e atingiu os filósofos idealistas. Para o senso comum, não há a possibilidade de uma análise do $e u$, de um $e g o$, ser aplicável aos outros eus, na medida mesmo que, cada $e u$ é um eu diferente dos outros.

Apesar de ser uma objeção do senso comum e para muitos poderia parecer insignificante, Ricoeur acredita que a filosofia idealista e, principalmente, a fenomenologia transcendental husserliana precisa reconhecer que o solipsismo é uma aporia que coloca em cheque a própria fenomenologia transcendental:

Ela é a continuação lógica da redução, mais precisamente da redução tal como ela foi compreendida na IV Meditação: não apenas tudo fica ali reduzido a um sentido de ser, mas todo sentido é, além disso, incorporado à vida intencional do ego concreto. Infere-se, portanto, da IV meditação que o sentido do mundo é somente a explicação do ego, a exegese de sua vida concreta. Este monadismo é que faz do solipsismo uma aporia interna, na medida em que o monadismo absorve toda alteridade, todo ser outro, em mim mesmo, de ora em diante é necessário que todo sentido nasça em (in) e a partir de (aus) mim (RICOEUR, 2009, p. 216-217).

Tendo a crítica ao solipsismo como ponto de partida, será preciso compreender basicamente o fenômeno da constituição do outro em si e em mim, Husserl tratará com duas exigências ao mesmo tempo na " $V$ Meditação". Por um lado, a partir da questão da redução fenomenológica, precisa encontrar o sentido do alter ego e precisar ao mesmo tempo como isso acontece "em mim" e "a partir de mim", ou seja, já que houve uma espécie de concentração de todo o fazer fenomenológico no eu (ego), é preciso apresentar as possibilidades que partem do eu para compreender o outro. Além disso, Husserl precisa também explicar a originalidade e especificidade da experiência do outro enquanto um não $e u$. Com isso, podemos perceber que a "V Meditação Cartesiana" consiste numa profunda reflexão sobre a alteridade ao mesmo tempo em que tenta compreender também a questão da subjetividade e, enquanto acompanhamos a análise de Ricoeur das ideias de Husserl, percebemos o percurso que a questão da alteridade passa no pensamento do autor francês, quer nas convergências, quer nas divergências com o autor alemão, mostrando a dinamicidade do método filosófico de Ricoeur.

\section{O eu, o outro e a subjetividade}

A reflexão sobre o outro possibilita um incremento na própria compreensão do $e u$ (ego), uma vez que ele não é um simples objeto que se apresenta à minha consciência, mas um "outro eu" distinto de mim. Ao 
mesmo tempo em que temos a noção da diferença, nos deparamos com a semelhança e dignidade desse outro eu. Ricoeur destaca o fato de Husserl partir de uma análise geral do que se entende como "experiência do outro" ou dos "modos de se dar" do outro "Não seria possível nenhuma descrição, nenhuma explicitação, nenhuma constituição se não se tomasse como guia o sentido terminal da experiência, a saber, a posição de uma transcendência diante de mim" (RICOEUR, 2009, p. 217). Aqui nos deparamos com três paradoxos, como chama o próprio Ricoeur.

Esse outro que transcende a mim se apresenta paradoxalmente como outra pessoa, capaz de experiência como $e u$, como outro sujeito, eu passo a fazer parte do seu mundo de experiência (primeiro paradoxo).

Com isso, o mundo como se apresentava a mim, ao $e u$, deixa de ser privado e passa a constituir-se num bem comum, ao mesmo tempo, esse "mundo" é tanto um fenômeno que se apresenta a cada um dos eus (eu mesmo e o outro eu) quanto são opostos por conta de cada experiência singular dos eus. Nessa perspectiva, aquilo que poderia ser considerado a "objetividade do mundo" torna-se, na verdade, um paradoxo (segundo paradoxo).

Por fim, quando o eu está frente a objetos culturais inegavelmente constituído por outros sujeitos e ao mesmo tempo, cada um dos objetos culturais são frutos de uma comunidade particular, os livros ou as ferramentas, por exemplo, cada uma remete ao mesmo tempo a um estranho que os fez e a um próprio comunitário (terceiro paradoxo).

Para Ricoeur, ao transformar esses pontos em paradoxos, especialmente, o terceiro, a fenomenologia husserliana depara-se com um problema, ao tentar clarificar e descrever tudo a partir de "minha vida intencional", ela acaba por espantar-se com aquilo que é evidente, no caso, com a experiência comunitária que possibilita o eu e alteridade. Nesse ponto, Husserl afirma e se interroga sobre o percurso que desenvolvemos para compreender como o eu e o outro eu estão relacionados:

Precisamos nos dar conta do sentido da intencionalidade explícita e implícita, em que, sob o pano de fundo composto pelo nosso eu transcendental, se afirma e se manifesta o alter ego. Precisamos ver como, em quais intencionalidades, sínteses e "motivações", o sentido do alter ego forma-se em mim e, sob as diversas categorias de uma experiência concordante do outro, afirma-se e justifica-se como "existente", e mesmo à sua maneira como estando presente "ele mesmo". Essas experiências e seus efeitos são precisamente fatos transcendentais de minha esfera fenomenológica: de que outra forma, a não ser interrogando-os, posso chegar a uma explicitação completa da existência do outro? (HUSSERL, 2001, p. 105). 
Por outro lado, e aqui vamos percebendo o próprio do pensamento de Ricoeur, a questão da subjetividade, nunca se aproxima de um solipsismo, pelo contrário, só há verdadeiro sentido e autenticidade numa subjetividade que compreende-se em relação, uma relação que parte do si mesmo (ipse), mas, que sempre encontra o outro, nas palavras do próprio Ricoeur,

tudo na minha experiência me fala dos outros, que o mundo é um mundo de cultura, que o mundo objeto está carregado de todos os olhares que se lançaram sobre ele, é possível perguntar-se se existe um mundo próprio, anterior à intersubjetividade, que mereça ainda o nome de mundo. Eu sozinho e as visadas intencionais do meu ser próprio, será que isto faz um "mundo"? (RICOEUR, 2009, p. 220).

Já no próprio título de um dos seus mais significativos livros, $\mathrm{S} i$ mesmo como um outro (Soi-même comme um autre), Ricoeur revela de maneira paradoxal como a subjetividade está fundada na relação.

No entanto, Husserl pretende "tratar da constituição transcendental das subjetividades estranhas, [...] por ser esta a condição da possibilidade da existência para mim de um mundo objetivo" (HUSSERL, 2001, p. 107). Continuaremos acompanhando, através do olhar de Ricoeur, o desenvolvimento do pensamento de Husserl. Num primeiro momento, o fenomenólogo alemão trata a objeção ao solipsismo como um argumento, ou seja, faz-se necessário realizar uma abstração do que é não eu (não ego), portanto, tudo o que é estranho ao eu deixa, inicialmente, de ser considerado.

Esse expediente metódico não implica que o $e u$ esteja isolado, mas, somente o "das mir Eigene, 'aquilo que me é próprio" é encarado

\begin{abstract}
$\mathrm{Na}$ atitude transcendental e na abstração constitutiva de que acabamos de falar, meu ego, o ego do sujeito que medita, não se confunde no seu ser transcendental próprio com o eu humano habitual; não se confunde com o $e u$, reduzido a um simples fenômeno, no interior do fenômeno total do mundo. Bem ao contrário, trata-se de uma estrutura essencial da constituição universal, que apresenta a vida do ego transcendental como constituinte do mundo objetivo (HUSSERL, 2001, p. 108).
\end{abstract}

Husserl, não pretende desconsiderar o outro, mas, há que ter em vista que o outro só ganha sentido a partir do próprio sentido que dou originaria e primeiramente a mim. Nesse ponto, o outro só pode ser considerado um estranho na medida que reconheço um próprio, o meu próprio eu. Para Husserl, a dimensão ôntica atinge o meu ego que provoca a transgressão da própria ipseidade, uma vez que não se trata somente de um objeto, nesse sentido, o outro se constitui como um reflexo do meu próprio ego. A 
experiência do "meu próprio $e u$ " nos impulsiona à reflexão, ou encontro, com aquilo que é estranho a mim. Ao radicalizar a reflexão sobre "aquilo que me é próprio" o ego é lançado ao paradoxo da separação e isso possibilita compreender a existência do "meu ego" e do "outro eu", "há na experiência do eu sozinho todos os sinais de uma transgressão em direção a um outro eu" (RICOEUR, 2009, p. 220). Essa reflexão dificilmente assalta os homens na atitude natural de contato com os outros, somente na atitude filosófica encontramos o espaço questionador propício para estabelecer os liames entre o mundo, como o dado, e o mundo-para-mim, nesse sentido, a experiência do mundo passa a ser considerada não num todo natural, mas, compreendo objetivamente que há o eu e existe o outro ${ }^{3}$.

Não há nesse percurso um sentido psicológico ou mesmo antropológico, na tentativa de abstração do ego, ele encontrar-se-á sempre entre a percepção do "meu ego" e do "alter ego". É bom lembrar que a abstração husserliana em questão, não significa um conscientismo ou um habitar somente na consciência ou mesmo no intelecto, para Husserl, esse ego está constituído num todo psicofísico "Em consequência dessa eliminação abstrativa de tudo o que é estranho a mim, restou-me uma espécie de mundo uma natureza reduzida à 'minha vinculação' - um eu psicofísico, com corpo, alma e eu pessoal, integrado a essa natureza graças a seu corpo" (HUSSERL, 2001, p. 112).

E como ressalta Ricoeur (2009, p. 224) pode causar espanto que paradoxalmente o caminho percorrido por Husserl demonstre que a partir da redução transcendental do ego causada pela crítica solipsista envidada pelo senso comum, acabemos por nos deparar com o "ôntico transbordante", Ricoeur ressalta a importância dessa conquista

[...] vê-se que a abstração, que revela o corpo próprio e a natureza própria, é muito mais que uma ficção didática. É também - e sobretudo - a conquista do sentido da encarnação: uma natureza minha é uma natureza centrada em meu corpo. Tendo-se tornado a esfera de exercício de meus poderes, ela é o que eu posso ver, tocar, ouvir. Deste modo a redução à esfera do próprio faz "surgir de novo" (herausstellen) o corpo como carne. Até aqui, este era sempre o órgão não observado, o órgão atravessado por meus atos, e estes terminavam nas coisas. De ora em diante, o "próprio" é minha carne (RICOEUR, 2009, p. 224-225).

\section{Tempo, consciência e memória}

\footnotetext{
${ }^{3}$ Essa é a experiência de sentido que caracteriza o percurso do reconhecimento de si no pensamento de Husserl e que, mesmo com diferenças significativas de delimitação e aprofundamento, também estará delineada no pensamento de Ricoeur.
} 
Algo importante a se destacar, está no fato de que no processo de percepção do $e u$, enquanto um próprio, nos deparamos também com a temporalidade imanente da experiência de ser (existir) no mundo e estar envolto na corrente de todas as propriedades, percepções, auto-percepções e mesmo explicitação do $e u$, que se dá, no presente e só capta aquilo que se dá no presente do vivente (do $e u$ ), aqui a questão da memória entra em ação, na medida mesma em que a percepção do passado desvela-se somente em mim e para mim "da maneira mais original que se pode conceber - na e pela lembrança" (HUSSERL, 2001, p. 116). A lembrança funciona como uma garantia para o eu na medida em que

Seja o que for que eu tenha mostrado constantemente, essa explicitação se efetua em grande parte por meio de atos de consciência que não são de forma alguma percepções dos momentos correspondentes de minha essência própria. A corrente do vivido, na sua qualidade de corrente, onde vivo como eu idêntico, só pode tornar-se acessível a mim da seguinte maneira: nas suas atualidades, inicialmente, e em seguida nas suas potencialidades, que, de forma visível, me são igualmente essenciais e próprias. Todas as possibilidades do gênero eu posso ou eu poderia - posso desencadear essa ou aquela série de estados vividos, posso prever ou olhar para trás, posso penetrá-las desvelando-as nos horizontes de meu ser temporal -, todas essas possibilidades pertencem claramente de maneira essencial e própria a mim mesmo (HUSSERL, 2001, p. 116).

Conforme Husserl, essa explicitação do $e u$ em si mesmo, na medida dos movimentos interiores da consciência, têm na experiência original que está intimamente ligada ao tempo e, uma vez que é uma explicitação no presente e é sempre no presente, é perpassada pelo passado e pelas lembranças, por isso, podemos afirmar que a subjetividade é uma experiência de interioridade (na relação) e a memória possibilita no seu percurso, uma vez que a lembrança é do passado, também o entendimento de que a memória está enquanto potência humana do eu no presente. Assim, essa constitui, portanto, não somente uma chave para a compreensão do $e u$, mas, também para a apreensão do outro. Ora, na corrente de explicitação do $e u$ através da temporalidade (do passado e do presente) que são as formas nas quais o ego existe é possível falar em uma "universalidade da essência", assim

Desse a priori apodíctico universal, na sua generalidade indeterminada, mas determinável, participa toda a explicitação dos dados egológicos particulares, como, por exemplo, a evidência - por mais imperfeita que seja - da lembrança que cada um tem de seu passado próprio (HUSSERL, 2001, p. 117). 
A abstração inicialmente proposta por Husserl nos leva numa ampliação da experiência primeira, na medida em que nos conduz de uma aparente redução à plenitude do ego. Se a natureza, mundo, apresentava-se como um espetáculo estranho, ao "tomar posse" do sentido de minha carne, eu experimento a participação nesse conjunto de coisas que consiste naquilo que é inicialmente estranho a mim, neste "fora de mim", a realidade da corporeidade indivisa do ego, possibilita ligar com a dialética "fora de mim" e "em mim", provocando a efetivação do outro, desse estranho "no próprio" e "fora do próprio", a corporeidade realiza o estar no mundo e a efetividade da relação.

\section{Corpo, memória e alteridade}

No caminho percorrido até aqui, Husserl nos faz caminhar pela compreensão de uma experiência do $e u$ que, passo a passo, se liga à experiência do outro. Há na experiência originária do próprio eu existe uma transgressão para o outro. Esse outro, sempre entendido, no caso de pessoas, como um "outro eu". Esse movimento é importante para a compreensão da subjetividade em Ricoeur, uma vez que ele demonstra que "Nele se equilibram as duas exigências da fenomenologia: o respeito à alteridade do outro e o enraizamento dessa experiência de transcendência 'na' experiência primordial” (RICOEUR, 2009, p. 227). Aqui há uma evidente superação do solipsismo e de qualquer crítica neste sentido, sem perder de vista o assumir de um próprio afirmado pela egologia "pode-se explicar a transgressão da esfera do próprio, confirmando ao mesmo tempo o primado da experiência originária do eu" (RICOEUR, 2009, p. 227).

Mais claramente, o eu se apercebe de si mesmo numa espécie de "autoapercepção mundanizante" o que equivale dizer que a consciência temse como um ente intramundano, de "modo que aqueles que são 'outros para mim não fiquem isolados, mas que, ao contrário, se constituam, na esfera que me pertence (bem entendidos), uma comunidade de eus que existem uns com os outros e uns para os outros, e que engloba a mim mesmo" (HUSSERL, 2001, p. 121), Husserl apresenta três graus de articulação entre a percepção do outro e a apercepção mundanizada do $e u$, com isso temos três graus da constituição do outro.

O primeiro grau, a percepção ${ }^{4}$ do outro que se me apresenta, está relacionada com um corpo, no entanto, na minha experiência primordial, o

\footnotetext{
${ }^{4}$ Husserl define a percepção da seguinte maneira: “A percepção não é um raciocínio nem um ato do pensamento. Toda percepção, pela qual concebemos e percebemos de maneira imediata os objetos que nos são mostrados, como o mundo de nossa vida cotidiana que se oferece ao nosso olhar, os objetos dos quais não compreendemos imediatamente o sentido e os horizontes, contém uma intencionalidade que remete a uma 'criação primeira', em que o objeto de sentido análogo era constituído pela primeira vez” (HUSSERL, 2001, p. 124$125)$.
} 
meu corpo é o único corpo que experiencio como carne, logo, para que esse outro corpo diante de mim ganhe sentido, entra em cena a transferência aperceptiva de minha carne, nesse caminho rumo à "constituição do mundo objetivo",

ao ter a experiência do outro dizemos, em geral, que ele está ali, ele mesmo, "em carne e osso" diante de nós. Por outro lado, esse caráter de "em carne e osso" não nos impede de concordar, sem dificuldades, que este não é o outro $e u$ que nos é mostrado no original, na sua vida, seus próprios fenômenos, nada do que pertence a seu ser próprio. Porque se fosse esse o caso, se aquilo que pertence ao ser próprio do outro estivesse acessível para mim de maneira direta, isso seria apenas um momento do meu ser a mim, e, no final das contas, eu mesmo e ele mesmo, nós seríamos o mesmo. O mesmo aconteceria com seu organismos se ele não fosse outra coisa senão um "corpo" físico, unidade que se constitui na minha experiência real e possível e que pertenceu à minha espera primordial como formada exclusivamente por minha "sensibilidade" (HUSSERL, 2001, p. 122-123).

Para aprofundar o sentido da analogia a partir do corpo, Husserl lança mão da presentificação, ou seja, para que a representação da carne do outro seja reconhecida como um fora de mim, faz-se necessário a autopercepção do próprio, sendo assim, a presentificação pode ser algo imagético e também pode ser compreendida como uma autopresentificação. Um objeto ou pessoa pode apresentar-se de modo intuitivo, ser simbolicamente representado e estar somente adiante de mim, ainda vazio de significado. Com isso, entendemos que a apercepção do $e u$ bem como do outro passam por um apresentar-se ao próprio eu de modo distinto, mesmo sendo corpos e estando presentes, a presentificação dos dois se dá diferenciadamente "O outro é outro não somente porque suas vivências não me podem ser dadas de forma original, mas também, principalmente, porque temos a experiência dele em uma situação subjetiva que, por princípio, não pode ser minha" (COELHO JR, 2003, p. 190-191).

Por isso, o segundo grau de articulação entre a percepção do outro e a apercepção mundanizada do eu passa pela concordância do comportamento, pela equiparação das expressões que o outro pode representar: "o organismo estranho afirma-se no decorrer da experiência como organismo verdadeiro, unicamente por seu 'comportamento', que se modifica, mas que é sempre concordante [...] esse comportamento tem um lado físico que apresenta o psíquico como seu indicador" (HUSSERL, 2001, p. 128). Se a analogia confirma que o outro também é um eu, a concordância do comportamento possibilita antecipar ao visar um outro eu, não como um próprio, mas, como um outro eu semelhante a mim. Sobre esse ponto, relacionando a analogia e a concordância dos signos expressivos, Ricoeur comenta: "enquanto continua sendo um análogo de 
mim mesmo, o outro não passa de uma modificação do meu eu; mas ao se mostrar em face de mim, num comportamento concordante, torna-se de verdade um 'outro', um 'estranho' (ein Fremdes)" (RICOEUR, 2009, p. 233). Inclusive, Husserl acredita que é essa acessibilidade indireta do outro que possibilita, para nós, a existência desse outro, "ele aparece de maneira necessária no meu 'mundo' primordial, na qualidade de modificação intencional do meu eu" (HUSSERL, 2001, p. 129).

Husserl realiza uma interessante "digressão" a partir das noções de presente e passado em que se dá a articulação entre a percepção do outro e a mundanização do $e u$. Partindo da noção interior que o $e u$ tem do que "me pertence", quando temos essa percepção de modo vivo, estamos no presente, o "meu passado é mostrado, de maneira indireta, pela lembrança somente, e se apresenta com o caráter de um presente passado como modificação intencional do presente" (HUSSERL, 2001, p. 129). A confirmação disso se dá pela experiência que temos desse passado e que através das sínteses concordantes das lembranças constitui o passado propriamente dito, assim, mesmo com as modificações que se dão nessa percepção, até por conta do passado transcender as lembranças do presente, a comparação com o mecanismo de percepção do eu e do outro eu podem ser encontradas, na medida que "o ser do outro que eu apresento transcende meu próprio ser no sentido 'daquilo que me pertence' de maneira primordial" (HUSSERL, 2001, p. 129).

Husserl encara a memória, por conta de sua relação com o tempo, como essa capacidade primordial de diferenciar, em mim, o passado do presente vivo, como uma primeira experiência da diferenciação do $e u$ e o outro

\begin{abstract}
Da mesma maneira que o meu passado se forma no meu presente vivo, no campo da "percepção interna", graças às lembranças concordantes que se encontram nesse presente, e também, graças às apresentações que aparecem na minha esfera primordial e são motivadas pelos conteúdos dessa esfera, posso constituir no meu ego um ego estranho, o que quer dizer que posso constituí-lo em reapresentações de um tipo novo, que têm como correlato um outro gênero de modificação. No entanto, quando se trata de reapresentação no interior da minha esfera de vinculação, o "eu-central" que lhe pertence não é outro senão eu mesmo, enquanto a todo aquele que me é estranho pertence um eu apresentado, que não sou eu mesmo, mas que é minha modificação, um outro eu, que permanece intimamente ligado aos horizontes apresentados de seu ser concreto (HUSSERL, 2001, p. 129-130).
\end{abstract}

No terceiro grau, entra o elemento da imaginação que, como vimos, é um elemento que já está contido na presentificação, uma vez que essa pode trazer novamente a lembrança de algo que, imageticamente ou imaginariamente torna-se presente e que pode caracterizar a distinção. Não 
entraremos aqui na discussão sobre o tempo em Husserl, mas, não é difícil perceber que a presentificação e o tempo são elementos que estão em parceria, sem perde de vista que a imaginação também entra nessa mesma relação, uma vez que

\begin{abstract}
a imaginação serve, pois, para 'ilustrar', para 'presentificar', o nexo essencial que ofereceu o primeiro grau da constituição do outro. Mas, em vez de preencher pela percepção do comportamento [segundo grau] esta visada analogizante, eu a preencho pelas criações livres da imaginação e assim dou à transferência associativa de mim ao outro, não somente a vivacidade da imagem, mas a sua independência em face de minha perspectiva atual. A ficção é esta libertação da minha perspectiva e essa transferência para uma outra perspectiva (RICOEUR, 2009, p. 234).
\end{abstract}

A imaginação ${ }^{5}$ proporciona e reintroduz neste percurso a reflexão. Muito do que apontamos até agora no desenvolvimento do pensamento de Husserl sobre a questão da subjetividade e do outro, passou pela experiência, a percepção propriamente dita. A imaginação traz de volta a perspectiva de comparar reflexivamente aquilo que era inicialmente vazio, pois somente o corpo "puro" ainda pouco distinto do "meu corpo". Daí, no processo passar a ter sentido analógico e passa pela concordância de comportamento, ganhando assim um certo grau de vida e que, no movimento de imaginação, passa a contar com a reflexão que visa a relação e coloca-se a questão sobre o e "se eu estivesse lá", lá no mesmo lugar desse outro que se me apresenta. Nessa dinâmica, progride-se "do vazio para o cheio, a visada de uma vida estranha sem, no entanto, essa transgressão da esfera do próprio me dar no original o vivido do outro" (RICOEUR, 2009, p. 234). Para Husserl, na esfera primordial da percepção do próprio corpo, nós vivemos uma experiência em que as potencialidades do eu e do outro se encontram em uma relação de diferenciação, até mesmo por conta da percepção espacial "meu corpo, que se relaciona consigo mesmo, é mostrado no modo do aqui; qualquer outro corpo - e também o corpo do outro -, no modo do ali" (HUSSERL, 2001, p. 130) que está submetida às variações livre de perspectivas, mas, sem perder essa relação com o espaço e, como vimos, com o tempo, proporcionando, assim, cada vez mais, um grau de diferenciação entre o eu e o outro eu, na mundanização.

Mesmo com essas aparentes conquistas, tanto Husserl como Ricoeur, concordam que há ainda um limite neste desenvolvimento do pensamento husserliano sobre a constituição do outro. Por isso, precisamos ir adiante na compreensão da natureza intersubjetiva da alteridade.

\footnotetext{
${ }^{5}$ A imaginação quando distinta da memória no que se refere à questão epistemológica, não constitui em algo negativo.
} 
Algo que devemos ter sempre em mente consiste na própria especificidade da relação eu-outro, muitas vezes, o senso comum costuma identificar essa relação com base na igualdade, ou melhor, na reciprocidade. No entanto, para autores que pensam a alteridade, a relação eu-outro está fundamentalmente ligada à assimetria, essa desproporção na relação constitui um dos maiores problema para Husserl, até aqui, o outro na " $V$ Meditação Cartesiana", tem a sua existência somente como derivação do $e u$, algo com que só existiria um ego e todos os outros são multiplicações por associação. Neste ponto, a percepção da comunidade proporciona o desenvolvimento de uma compreensão, ainda a partir do corpo, de um perspectivismo que possibilita captar a percepção desse outro, percebendo também as diferenças e mesmo assimetrias na relação:

meu corpo é a origem zero de um ponto de vista, de uma perspectiva, que dá uma orientação determinada ao sistema de minhas experiências. Compreendo então que o outro tem uma outra experiência que orienta de modo diferente o seu sistema de experiências. Mas a dupla pertença do corpo do outro ao meu sistema e ao dele me permite compreender que o mesmo objeto pode ser percebido através de duas perspectivas diferentes (RICOEUR, 2009, p. 238).

Cada um dos eus (egos) apreende o mundo de uma perspectiva, de um ponto de vista diferente, uma vez que parte da experiência originária de cada $e u$, mais
importante ainda é a elucidação da comunidade que se forma em graus diferentes e que, graças à experiência do outro, logo se estabelece entre mim - ego psicofísico primordial que age no meu corpo primordial e que por meio dele - e o 'outro, mostrado na experiência da apresentação; ou, se considerarmos a coisa de maneira mais concreta e radical, da comunidade que se estabelece entre mim e o ego monádico do outro. $\mathrm{O}$ que se constitui em primeiro lugar sob a forma de comunidade e serve de fundamento a todas as outras comunidades intersubjetivas é o ser comum da "natureza", aí incluído o do "corpo" e o do "eu psicofísico" do outro, emparelhado com o meu próprio eu psicofísico (HUSSERL, 2001, p. 134).

Há uma reciprocidade aqui das experiências comuns frente à natureza, ao mundo que, como vimos, passa pela experiência originária do $e u$ e da presentificação, no entanto, Husserl reduz essa dinâmica ao modelo de identificação, como uma síntese entre as duas consciências. Isso torna a "identificação de um mundo que se apresenta e de um mundo presentificado" numa quase dualidade de um mundo que se apresenta à consciência e de um mundo que se presentifica frente a essa mesma consciência, assim um retrato e uma lembrança, por exemplo, oferecem a 
“possibilidade de 'voltar ao mesmo objeto' dá à série inteira das percepções sucessivas o caráter de uma visada do mesmo".

Podemos perceber a importância do tempo e, por consequência, da memória para compreensão desta questão. O tempo acaba por funcionar como um unificador das percepções e perspectivas, tanto das consciências quanto do mundo (duas consciências, eu e o outro, e um só mundo). Mesmo que as percepções sejam distintas, mesmo que a presentificação se dê de modo conflituoso entre o eu e o outro, tudo se dá dentro de uma mesma "comunidade temporal", o tempo materializa a coexistência dos vários eus (por Husserl, esse eu chega a ser tratado como uma mônada, como uma unidade indivisa e que ao longo do percurso, vai abrindo-se cada vez mais à relação), afinal de contas, "há um só tempo como há um só mundo: o tempo privado, o tempo de cada mônada, ordena-se em relação a um tempo comum objetivo do que é um "modo de aparecer"' (RICOEUR, 2009, p. 241). O tempo como o mundo permitem uma unidade das realidades que aparece distintas nos eus originários, mas, que são constituídas pela intersubjetividade proporcionada pela relação dos eus na comunidade, a coexistência dos dois se dá na "criação de uma forma temporal comum, e qualquer tempo primordial adquire espontaneamente a significação de um modo particular da aparição original e subjetiva do tempo objetivo" (HUSSERL, 2001, p. 142). Assim, eu e outro, estão ao mesmo tempo unidos, pelo efeito da presentificação (do outro) e pela objetividade do tempo comum da mundanização, numa comunidade temporal que constitui um mundo, com espaço e tempo cósmicos, ou seja, "a subjetividade passaria à esfera da intersubjetividade, através de uma experiência co-constituinte, que pertence a todos e a ninguém em particular" (COELHO JR, 2003, p. 188-189).

Ricoeur identifica, nesses passos de Husserl, aquilo que ele mesmo chama, percurso do reconhecimento de si e do reconhecimento mútuo e que estão indissociáveis ao seu pensamento, como uma experiência iniciada já com o pensamento de Husserl, ou seja, desde o criticado solipsismo, o pensador alemão, passo a passo, chega à comunidade. Para o reconhecimento da subjetividade faz-se necessário à relação.

Mesmo tendo críticas à descrição husserliana da comunidade, Ricoeur reconhece esse percurso do eu monódico à comunidade. Apesar do desenvolvimento do tema do "mundo da vida" realizada, especialmente, na pequena conferência sobre as ciências intitulada A Crise das Ciências Européias e a Fenomenologia Transcendental, Husserl ainda nas Meditações cartesianas, inicia a sua exposição do tema da comunidade no caminho do $e u$ e do outro a partir, não de uma comunidade histórica, mas, faz referência a questão da "reciprocidade dos pontos de vista" e a "equalização objetivante", no percurso até aqui, Husserl demonstra que somente o eu é um eu enquanto o outro eu é um outro, "impõe-se explicar 
essa equalização mediante a qual me torno um outro para os outros, um outro entre os outros" (RICOEUR, 2009, p. 243).

Husserl faz referência à psychè que, juntamente com o corpo, realiza uma espécie de reificação do ego. Assim, o mundo me aparece como uma reciprocidade de outros no nível psíquico, ocasionando a percepção de que sou uma psychè entre outras, iguais enquanto psychè, no entanto, distintas porém ligadas "Cada homem aparece a cada outro homem de maneira intrapsíquica" (RICOEUR, 2009, p. 244). Nesse ponto, temos introduzida a noção de uma constituição psíquica do mundo objetivo que possibilita, portanto, a equalização objetivante e, por consequência, compreendemos que o $e u$ não aparece somente como carne, mas, também enquanto psychè $\mathrm{e}$ somente a partir desse nível, entendemos os outros como psiquismos equalizados, na medida em que, o eu e o outro estão separados, mas, também são recíprocos possibilitando, por sua vez, a intersubjetividade que é um fenômeno humano e que está sustentada pela realidade psíquica. Ricoeur nos lembra que Husserl ao longo de sua obra deixa claro que a pessoa é "correlativa da comunidade e de suas 'propriedades habituais'. Dirse-ia bastante bem que a pessoa vem a ser o ego considerado em seus hábitos comunitários" (RICOEUR, 2009, p. 246).

\section{Subjetividade e intersubjetividade}

Husserl desenvolve uma caminhada rumo ao concreto, do aparente solipsismo inicial até a noção clara da pessoa como fruto da comunidade, ou seja, do ego monódico ao eu relacional. Não a toa afirma o autor das Meditações cartesianas: "cada subjetividade particular e a origem de seu valor intersubjetivo que permanece inerente ao mundo da comunidade de vida pressupõem, portanto, que uma comunidade humana existe" (HUSSERL, 2001, p 148), daí podemos perceber com clareza que Husserl rompe com o sujeito impessoal moderno, quer de Descartes, de Kant e mesmo do neokantismo muito comum no início do século XX.

Curiosamente, essa problemática do próprio e do estanho que acontece no nível pessoal, atinge também os grupos históricos, quer familiar, quer cultural, se o corpo é o "grau zero" do eu, da comunidade humana, o ponto inicial é a minha comunidade "[s]omos eu e minha cultura que formamos aqui a esfera primordial em relação a qualquer cultura 'estranha'. Essa última é acessível a mim e àqueles que formam comigo uma comunidade imediata, por uma espécie de "experiência do outro" (HUSSERL, 2001, p. 147-148).

No entanto, não podemos perder de vista a relação, também destacada por Ricoeur, já no pensamento de Husserl, entre interioridade e subjetividade. A interioridade não exclui, muito pelo contrário, ela potencializa, quando a subjetividade é compreendida de maneira autêntica, 
uma "tomada de consciência universal de si mesmo", nas palavras final de Husserl nas Meditações cartesianas, lemos:

O oráculo délfico (conhece-te a ti mesmo) adquiriu um novo sentido. A ciência positiva é uma ciência do ser, a qual se perdeu no mundo. É preciso de início perder o mundo pela (epochè), para reencontrá-lo em seguida numa tomada de consciência universal de si mesmo. Noli foras ire, disse Santo Agostinho, in te redi, in interiore homine habitat veritas $" 6$ (HUSSERL, 2001, p. 170).

Precisamos destacar que grande parte do esforço husserliano para compreender a relação eu-outro e superar o problema do solipsismo, está diretamente ligado ao conceito de intersubjetividade e, consequentemente, a própria compreensão do que seja a subjetividade.

Descartes (2004), com o cogito instaura a perspectiva do sujeito como fundamento das certezas, mesmo que o mote inicial do desenvolvimento do pensamento cartesiano esteja na dúvida

[...] com sua obstinação em querer duvidar, dá mostras de uma vontade de certeza e verdade - não faremos distinção entre essas duas expressões neste estádio -, que confere à própria dúvida uma espécie de oriente [...]. Ao contrário, o que motiva é a vontade de encontrar; e o que eu quero encontrar é a verdade da coisa (RICOEUR, 2014, p. XVII-XVIII).

Essa busca pelas certezas no próprio $\mathrm{eu}$, no cogito, dá a Descartes a condição de ser um pensador originário do conceito de subjetividade que estará mais desenvolvido em Kant, dimensionando-o para a condição de uma subjetividade transcendental, um eu permanente, autorreferente, capaz de, ao realizar um julgamento para saber os próprios limites da razão, descobrir assim, um eu puro que estaria fundamentado na racionalidade. Hegel levará isso ao paroxismo de instituir um pensamento que tem como tarefa pensar-se a si mesmo

\begin{abstract}
o pensamento é um deus ciumento que apenas a si se expressa como essencial e nada pode suportar a seu lado. [...] $\mathrm{O}$ pensamento objectivo, o universal, é o fundamento, a substância, que reside e permanece na base, não se altera, mas unicamente em si ingressa, em si se afunda e se manifesta; com efeito, ingressar em si é trazer o seu interior à consciência, manifestar-se; e manifestar-se é o ser do Espírito (HEGEL, 2006, p. 196-197).
\end{abstract}

No caminho percorrido por Husserl, encontramos o eu como consciência e também como corpo, causando no reconhecimento do outro, a

\footnotetext{
6 "Não saias, volta a ti mesmo, no interior do homem habita a verdade".
} 
compreensão da existência de uma comunidade de eus, assim, para Husserl, o eu se pode ser considerado como uma mônada inicialmente, encontra ao fim uma dimensão de nós que "comporta essencialmente uma harmonia" de eus coexistentes que constituem um equilíbrio no entrecruzar da subjetividade na intersubjetividade que ultrapassa o eu e o outro eu.

No esforço de sair do solipsismo do ego, ao chegar na comunidade intersubjetiva dos eus, Husserl percorre um caminho em que o outro é tratado como alter ego, no entanto, nesse percurso, mesmo levando em consideração a comunidade como um avanço na subjetividade transcendental, Husserl corre o risco de cair numa outra forma de "prisão", "para sair do solipsismo do eu, ele [Husserl] poderá ter constituído, no final das contas, um solipsismo do nós. Dessa maneira, as relações interativas da comunidade intersubjetiva poderão ter caído na rotatividade circular, que não encontra saída" (SOUZA, 2007, p. 71). Apesar do avanço evidente da concepção de Husserl, Ricoeur pretende ir mais adiante na reflexão sobre a alteridade, evitando o risco de tornar a comunidade, uma prisão ou numa fonte de injustiça, quer pela negação do $e u$, quer pela manipulação.

\section{A alteridade no centro da ipseidade: a perspectiva ricoeuriana}

Ricoeur fala de uma relação dialética entre ipseidade e alteridade que é fundamental, tanto para uma conexão entre reflexão e análise quanto para uma compreensão ontológica, que deve contar com uma oposição interna (dialética) entre ipseidade e mesmidade.

Ricoeur não trata a alteridade como um acrescentar de fora à ipseidade, ela está constitutivamente no centro da ipseidade. Nesse sentido, duas ordens de reflexão sobre a alteridade são trazidas à discussão. O primeiro, implica no jogo entre o discurso fenomenológico e o ontológico em que constatamos a relação da alteridade no centro do que seja a ipseidade, assim, o "correspondente fenomenológico da metacategoria de alteridade é a variedade das experiências de passividade, mescladas de múltiplas maneiras ao agir humano" (RICOEUR, 2014, p. 375), com efeito, o termo alteridade estaria reservado ao discurso especulativo e a passividade serviria para a atestação da própria alteridade.

Nisso já está anunciado o caráter polissêmico da alteridade (como também da ipseidade), uma vez que essa não reduz o outro à alteridade de um outrem. Esse caráter polissêmico se dá na medida em que há uma relação dialética entre o Mesmo e o Outro dentro da hermenêutica do si. Inicialmente, o Mesmo perde o seu caráter aparentemente unívoco quando posto em relação com a Ipseidade, assim, tanto a alteridade quanto a ipseidade são polissêmicas, na medida em que cada uma, dialeticamente, está em relação com o Mesmo ou com o Outro.

Ao colocar a alteridade no centro da ipseidade, Ricoeur acredita que esse jogo dialético que constitui o cerne dessa relação, retira do si mesmo o 
lugar do fundamento, com isso, estamos fora da egologia husserialiana e, especialmente, fora do Cogito cartesiano em que o si mesmo é exaltado e, ao mesmo tempo, fora também da perspectiva de um si mesmo humilhado, como na filosofia de Lévinas e de outras perspectivas anti-Cogito, ou como afirmado no prefácio do $O$ si-mesmo como um outro: "Sujeito enaltecido, sujeito humilhado: ao que parece é sempre por meio dessa inversão de pró e o contra que se faz a abordagem do sujeito; daí seria preciso concluir que o "eu" das filosofias do sujeito é atopos, sem lugar garantido no discurso" (RICOEUR, 2014, p. XXX). Para superar as dificuldades encontradas nesses antagonismos Ricoeur propõe uma reflexão a partir da hermenêutica do si sobre a questão dos usos do termo "se e do si nos casos oblíquos, o desdobramento do mesmo segundo o regime do idem e do ipse, a correlação entre s-mesmo e o outro que não o si-mesmo" (RICOEUR, 2014, p. XXX) que gerarão as relações da dialética ipseidade e mesmidade e da dialética da alteridade e ipseidade. Nesta última, no entanto, a atestação se dá ela mesma de modo partido, na medida em que a essa relação dialética só pode ser conhecida através de experiências dispares, na própria "diversidade de focos da alteridade".

Para entender melhor o que estamos analisando, Ricoeur associa ao tripé da passividade que é o mesmo da alteridade, ou seja, na passividade encontramos a experiência do próprio corpo, da carne, o que possibilita compreender o corpo como um mediador entre o si mesmo e o mundo, essa mediação dar-se em graus distintos de praticabilidade, o que significa dizer que são graus variáveis de estranheza [étrang(èr)eté].

[...] segue três direções na exploração do campo do outro na experiência da passividade-exterioridade. A primeira figura da passividade é a alteridade da carne "enquanto mediadora entre o si e mundo", mais ampla que a dimensão do "corpo próprio", e que produz as mais variadas experiências que podem ser traduzidas, brevemente, como a "diminuição do poder de agir", ao reverso da definição do homem capaz com "poder de agir e esforço para existir"; é assim que Ricoeur insiste sempre que o homem é atuante e sofredor. A segunda figura da passividade é a alteridade de outrem, do estranho, enquanto meu semelhante, que remete à questão da intersubjetividade, mas se vincula com as figuras anteriores da carne, no sofrimento que um homem causa a outro homem; deveria ser conduzida, pensa o autor, numa dupla superação: do critério meramente perceptivo de outrem, em Husserl, e do "critério imediatamente moral da injunção inerente ao apelo à responsabilidade", em Lévinas. A terceira figura da passividade é a alteridade do foro interior (Gewissen) "figurado pela voz da consciência dirigida a mim do fundo de mim mesmo", "o fórum de colóquio de si consigo mesmo" (LAUXEN, 2010, p. 53).

Aqui é possível entender que a passividade está relacionada com um nem precisar de um movimento, de uma ação anterior do $e u$, no próprio 
corpo dá para sentir-se em relação e, portanto, em alteridade, daí, retomarmos a noção clara da alteridade no centro da ipseidade. No próprio $e u$ é possível perceber as diferenças entre o corpo e a consciência. Por isso, podemos compreender que há a "passividade implicada pela relação de si com o estranho, no sentido preciso do outro do si, portanto a alteridade inerente à relação de intersubjetividade" (RICOEUR, 2014, p. 376).

Precisamos aprofundar mais a questão da relação constitutiva e ontológica da pessoa, na medida em que essa é constituída pelos aspectos físicos e psíquicos e quando falamos em corpo humano, estamos ao mesmo tempo falando de corpos e do meu próprio corpo, isso faz perceber a importância da organização da linguagem para a compreensão dessa relação dialética até mesmo no referenciar-me ao corpo. Ou seja, ao falar de corpo, os outros (corpos) e o meu corpo estão já aí em relação e, não dá para compreender o meu corpo apartando dos outros corpos. A linguagem pensa e fala do corpo/meu corpo em relação.

Essa questão também pode ser percebida na medida em que pensamos sobre a ação. Se uma ação humana não se dá no nada, ela terá que se dá no mundo, será um acontecimento que mesmo tendo um autor (o eu) pertencerá ao mundo, ou seja, notamos aí uma dependência entre o eu e o mundo quando de uma ação: "O corpo próprio é o lugar - no sentido forte do termo - desse pertencimento graças ao qual o si pode pôr sua marca nesses acontecimentos que são as ações" (RICOEUR, 2014, p. 377).

Algo interessante a destacar está no fato de que, a carne, o corpo pode ser um indicador do outro, mas, a carne em si mesma não é o objeto de uma escolha, de um querer, mas, de uma síntese passiva que possibilita as sínteses ativas

A carne é o lugar de todas as sínteses passivas sobre as quais se edificam as sínteses ativas, únicas que podem ser chamadas obras (Leistungen): ela é a matéria (hylé), em ressonância com tudo o que pode ser chamado de hylé em todo o objeto percebido, apreendido. Em suma, ela é a origem de toda a "alteração do próprio". Destas resulta que a ipseidade implica uma alteridade "própria", se é que se pode dizer, cujo suporte é a carne. Nesse sentido, ainda que a alteridade do estranho pudesse - por hipótese - ser derivada da esfera do próprio, a alteridade da carne lhe seria ainda preliminar (RICOEUR, 2014, p. 383).

Portanto, está na compreensão (pré-linguística) da minha carne e o mundo, que poderá ser edificada uma significação da ação que não se perca entre jogos e linguagem. Ao realizar a "mundanização da carne", em que ela aparece como um corpo entre outros corpos damos um passo na compreensão da alteridade não somente visada a partir do corpo e do mundo, como uma exterioridade, mas, também podemos perceber que a "minha carne só aparece como um corpo entre todos os corpos na medida 
em que eu mesmo sou outro entre todos os outros, numa apreensão da natureza comum, tecida, como diz Husserl, na rede da intersubjetividade" (RICOEUR, 2014, p. 385) que é o instaurador da ipseidade.

É preciso notar que há uma distinção paradoxal entre carne e corpo, na medida em que, minha carne está na dimensão pré-linguística enquanto meu corpo está numa dimensão comparativa. Por isso, podemos afirmar que existe no próprio si-mesmo, compreendido como totalidade, a evidência da relação ipseidade-alteridade. Dito de outro modo, sentimos na carne a dialética dessa relação.

A vista disso, a passividade implica também uma relação que parece ficar dissimulada pela evidência do mundo exterior e do outro, essa passividade implica a relação do si com o si-mesmo, no diálogo interior em que temos a consciência que relaciona-se na interioridade. Ao colocar a consciência como uma terceira, ao lado do corpo e do outro, na relação passividade-alteridade, Ricoeur, ao contrário do cogito exaltado, destaca mais uma vez que o eu não é "senhor em sua própria casa" e que a complexidade e densidade da alteridade compreende um extraordinário caminho e que encontra na própria consciência a atestação e unidade dessa relação.

Mas, não é só isso, ao realizar uma digressão a partir da concepção heideggeriana do Dasein em que o homem é o ser-aí, um ser lançado, entra em cena o caráter do peso específico da existência, em que é necessário o recolocar a si mesmo na abertura, no mundo. Se o Dasein constituí ao mesmo tempo o caráter distintivo de ser, um ser no mundo, há um íntimo do ser-aí e sua relação com o ser lançado no mundo. Esse estar lançado no mundo que pode carregar consigo até mesmo uma frustação, aparece também associada, em Heidegger (2002), ao tempo e, consequentemente, com a finitude, afinal de contas, o homem é um ser para a morte.

Se na alteridade primeira o $\mathrm{eu}$ depara-se consigo mesmo enquanto carne e corpo, com o trabalho da consciência em compreender-se, isso implica uma luta interior e exterior entre a existência e o ser no mundo, entre o ser e o deve-ser que torna a alteridade num paradoxo irrevogável da constituição do si-mesmo e pode nos levar a compreender a força de ser o simesmo como um outro.

Pensando sobre a espacialidade, Ricoeur questiona um certo peso na temporalidade que costuma nos dominar, especialmente, tem em mente as reflexões heideggerianas do Ser e Tempo e a sua ênfase quase exclusiva no tempo e o esquecimento do espaço, seriam uma recusa em realizar uma fenomenologia da carne. Essa pequena digressão ricoeuriana nos leva a perceber a importância das três dimensões da dialética da alteridade, na medida que ela está relacionada com o mesmo, o próprio e o outro, numa relação que nos faz perceber também a dimensão do corpo/carne, tempo, espaço, mundo etc, mas, dessa vez percebemos que não há somente uma busca ontológica pura para compreender isso, para o filósofo francês, essa 
reflexão deve nos levar para a perspectiva da ação. Como vimos, toda ação humana está em relação com o mundo.

A segunda significação da chamada por ele metacategoria da alteridade, a alteridade do outro, está estreitamente ligada à modalidade da passividade e de uma hermenêutica do si que coloca a relação si com o diverso de si como uma nova dialética do mesmo e do outro. Nesse ponto, percebemos que a reflexão fenomenológica dessa relação, possibilita entender que o diverso de si abre margem para a compreensão da diferença entre o ego e o si, na medida em que o "diverso de si afeta a compreensão do si" e essa diferença é marcada pelo fato do ego ser aquele que se coloca e o si ser aquele que se reconhece a partir dessas afeições.

Segundo Ricoeur, a passividade própria do si está em toda as análises possíveis, desde o plano linguístico, na medida em que o "discurso enquanto ele próprio é endereçado a..." e mesmo a autodesignação do agente da ação está indivisa da adscrição por um outro que, ao utilizar o acusativo, designa o autor das ações

\begin{abstract}
Nesse intercâmbio entre adscrição na segunda pessoa e autodesignação, pode-se dizer que a retomada reflexiva desse ser-afetado pela adscrição proferida por outrem se entrelaça com a adscrição íntima da ação a si mesmo. Esse entrelaçamento se expressa no plano gramatical pelo caráter onipessoal do si que circula entre todos os pronomes. $\mathrm{O}$ fato de o si ser afetado pelo outro que não o si é o suporte desse intercâmbio regrado entre as pessoas gramaticais (RICOEUR, 2014, p. 389).
\end{abstract}

Não a toa que poderíamos afirmar que, a ficção, enquanto "narrativa dos papéis sustentados pelos personagens" na relação entre leitor, personagens, narrador (geralmente na terceira pessoa) que tem os acontecimentos narrados na perspectiva em que o tempo e a ação estão integrados, acaba por afetar, num vínculo privilegiado o sujeito leitor. Tanto é assim que podemos falar, muitas vezes, de uma catharsis do leitor, que nessa "luta" narrativa-sujeito que lê encontra, na dimensão dos afetos. Assim, a recepção dessas narrativas que facilitam a compreensão das relações de afeição e oposição entre o eu e o outro, está numa dimensão do imaginário (simbólica) que contribui efetivamente para as trocas entre palavra e ação e demonstra que as seduções da ficção acaba por afetar efetivamente o real.

Esse percurso da narrativa que possibilita uma hermenêutica do si, nos leva, mais claramente quando associada a dialética da alteridade a perceber que pensar a alteridade no centro da ipseidade é estar no caminho inevitável da reflexão ética

Por fim, é no plano ético que o afeitar do si pelo outro assume os traços específicos que dizem respeito tanto ao plano 
propriamente ético quanto ao plano moral marcado pela obrigação. A própria definição de ética que propusemos - bem viver com e para outrem nas instituições justas - não é concebível sem que o projeto de bem viver seja afetado pela solicitude ao mesmo tempo exercida e recebida: a dialética da estima a si mesmo e amizade, antes de qualquer consideração sobre a justiça dos intercâmbios, pode ser inteiramente reescrita nos termos de uma dialética entre ação e afetação (RICOEUR, 2014, p. 390).

Algo importante a considerar sobre a ética de Ricoeur é que ela, ao contrário da solidão monódica husserliana; do fechamento ao outro das éticas modernas com o eu exaltado e do peso assimétrico das éticas anticogito, especialmente, a perspectiva levianasiana de um eu anulado, o filósofo francês pensa na dimensão de uma ética em que a reciprocidade constitui o ponto fundamental, mesmo que, como sabemos, o perdão tem forte peso no pensamento de Ricoeur, esse mesmo, está na dimensão da reciprocidade, de um passo em direção ao outro. Por isso, chama-nos a atenção a retomada da philautia aristotélica, ou seja, da amizade que começa por ser inicialmente "amigo de si" e entra na relação com o outro através de uma relação de amizade que carrega, em alguma medida, os correlativos de uma afeição pelo outro, como a de si para si e para o outro (amigo).

A evocação a Aristóteles passa especialmente pelo sentido da amizade como preparação para a justiça, entendida, como virtude para o outro e por conta da "reversibilidade dos papéis, cada agente é o paciente do outro. E, em sentido afetado pelo poder-sobre-ele exercido pelo outro, ele é investido pela responsabilidade por uma ação situada de imediato sob a regra da reciprocidade, que a regra de justiça transformará em regra da igualdade" (RICOEUR, 2014, p. 390-391). Portanto, todos nós protagonistas de nós mesmos - assumimos, em momentos distintos, o papel de agente (sujeito da ação) e de paciente (aquele que sofre a ação), por isso, a reciprocidade constitui um valor significativo para o plano ético, nesse sentido, o outro e o mundo, pensado como coletivo, está no cerne da alteridade.

\section{Considerações finais}

Muitas vezes, os estudos que tratam da alteridade partem da dimensão cultural e/ou social. Seguimos, aqui, pelo caminho da discussão husserliana da egologia, refletindo sobre o outro por um caminho de compreensão do próprio eu. Adotamos método semelhante quando refletimos sobre o $e u$, ou seja, refletir sobre o eu possibilitou que nós compreendêssemos a presença constante do outro na nossa mais primária constituição, no nosso mais primeiro reconhecimento. Não é preciso um 
momento posterior para descobrir a "força" do outro, como atração, como distinção, como relação originária.

A alteridade aparece, em alguma medida, como um outro momento do si mesmo, entrelaçado no próprio eu. A perspectiva de Husserl nos ajuda a compreender dimensão significativa da alteridade. No pensamento de Ricoeur coloca a alteridade no centro da Ipseidade. No centro daquilo que é mais próprio em nós, está a alteridade; ser nós mesmos pressupõe ser em relação.

Ricoeur, desde o início do Si mesmo como um outro, chama a atenção para a ligação dialética fundamental entre a ipseidade e a alteridade. Precisamos destacar que, na relação entre ipseidade e alteridade, esta última não é acrescentada de fora à primeira; isso propicia uma nova compreensão da questão da alteridade, não mais entendida como um momento da relação com o outro, mas compreendida agora dentro da própria subjetividade, como fato originário do eu. 


\section{Referências bibliográficas}

COELHO JR, N. E. Da intersubjetividade à intercorporeidade: contribuições da filosofia fenomenológica ao estudo psicológico da alteridade. Psicologia USP, Vol. 14, No .1, 2003. Disponível em: http://www.revistas.usp.br/psicousp/article/view/42396. Acessado em $06 \mathrm{de}$ julho de 2015.

DESCARTES, R. Meditações sobre filosofia primeira. Campinas, SP: Editora da Unicamp, 2004.

HALBWACHS, M. A memória coletiva. São Paulo: Centauro, 2006.

HEIDEGGER, M. Ser e tempo. Petrópolis: Vozes, 2002.

HEGEL, G. W. F. Introdução à história da filosofia. Lisboa, Edições 70, 2006.

HUSSERL, E. Meditações cartesianas. São Paulo: Madras Editora, 2001.

LAUXEN, R. R. O alcance ontológico da fenomenologia da ação de Paul Ricoeur. Revista Estudos Filosóficos $\mathrm{n}^{\circ} 5$ /2010. Disponível em http://www.ufsj.edu.br/portal2-

repositorio/File/revistaestudosfilosoficos/art4-rev5.pdf acessado em 08 de julho de 2015.

RICOEUR, P. Na escola da fenomenologia. Petropólis-RJ: Vozes, 2009.

O si-mesmo como outro. São Paulo: Editora WMF Martins Fontes, 2014. 